\title{
Research on the Construction of Enterprise Financial Shared Service Center Based on Cloud Computing
}

\author{
Cao Changshuai ${ }^{1}$,Jin Yuchan ${ }^{2}$, HuangHuang ${ }^{*}, 3$ \\ ${ }^{1}$ Nanjing University of Posts and Telecommunications Nanjing, Jiangsu, 210023, China \\ ${ }^{2}$ Southwest University Westa Chongqing, 400700, China \\ ${ }^{3}$ HUAQIAO UNIVERSITY QuanZhou, FuJian, 362000, China
}

\begin{abstract}
Multinational companies and large enterprise groups in the economic globalization and information era have high financial costs, difficult management, and poor financial information quality. In the financial sharing service, it centralizes and centralizes the branch's accounting, expense reimbursement, fund payment and other services, and uses cloud computing technology to effectively improve its data storage capacity and calculation and analysis capabilities, thereby effectively solving the company's financial management problems. This paper focuses on the financial management problems of large multinational enterprises, studies cloud computing, financial sharing services and other related theories and technologies, and discusses in depth the advantages, construction principles and construction processes of financial sharing services in cloud computing environments. Reengineering, repayable process reengineering, and receivables process discussed the construction of a cloud-based financial shared service center to provide a reference for related companies to improve their financial management models and obtain good business results.
\end{abstract}

\section{Introduction}

Economic globalization has become an important development direction of the world economy. Computer information technology has achieved rapid development, which has greatly promoted the development of productive forces in various countries and has continuously expanded the business scale of enterprise groups [1]. After the business scale of large enterprises continues to expand, the number of branches and subsidiaries continues to increase, making these large enterprise groups face more and more problems. The continuous expansion of the enterprise scale has caused problems such as high financial costs, low efficiency, and poor information quality [2]. With the continuous expansion of enterprise business, its operation and management are becoming more and more complicated, which has caused the company's management costs to increase sharply. Due to the lack of unified business rules and business standards to regulate, the transparency and control of large-scale enterprises will be weakened the branches and subsidiaries are closely related, and the various business risks of the branch companies will increase the business and financial risks of the enterprise group.

Cloud computing-based financial sharing service, the new financial management model, through the collection and integration of similar businesses in the enterprise, unified processing of the collected business, in order to improve the efficiency of the enterprise [3]. With the help of cloud computing technology, the financial sharing model in the new era greatly improves the data storage and computing capabilities of the financial sharing service center, effectively guarantees data security, and helps enterprise groups integrate financial resources, reengineer financial management processes, and improve the efficiency of financial business processing. In order to better apply cloud computing technology in the financial sharing service model, this paper studies the construction of a financial sharing center based on cloud computing, with a view to forming scientific, objective, and certain application value achievements for the future construction of financial sharing service centers Certain reference [4].

\section{Cloud computing overview}

\subsection{Basic concepts of cloud computing}

Google first proposed the concept of cloud computing, and many scholars and institutions have tried to describe cloud computing from different perspectives, resulting in many definitions of cloud computing, and there is no universally accepted unique definition. Cloud computing is a pay-asyou-go model that provides convenient network access on demand. It can easily enter a resource-sharing pool with little management effort or little interaction with a service provider. It is a supercomputing service model that applies virtualization technology, provides services according to customer needs, and centralizes distributed computing resources to work together. Under normal circumstances, this understanding of cloud computing has been accepted 
by a wide range of people and has been widely recognized [5].

\subsection{Basic technical characteristics of cloud computing}

Cloud computing is a new type of computer Internet technology that can integrate physical resources and use virtualization technology according to user resources and computing needs to arrange virtual resources in real time. From the user's perspective, cloud computing has the following characteristics [6].

The computing power is very powerful. In the largescale cloud computing service platform, hundreds of thousands of servers are configured, combined with extremely powerful computing capabilities [7].

2.2.1 Resource virtualization. In cloud computing, the mainstream model is "more virtual one" or "more virtual more". It integrates many physical servers to provide one or several services, greatly improving the computing and processing capabilities of the cloud. Cloud computing presents virtual resources in the form of resource pools. Users do not need to pay attention to the location of the resource pool used in the "cloud", but only need to connect network terminals to the cloud network.

2.2.2 Highly reliable and safe. In a cloud environment, it can effectively reduce risk indicators. Both the public cloud and the private cloud are deployed in different regions. The failure of a single node or a few nodes will not affect the overall service.

2.2.3 On-demand service. End users only need to purchase the corresponding services according to their needs. The cloud service is obtained completely through self-service behavior, and the interface presented to the user is very simple and easy to use.

Flexible expansion. In the cloud computing environment, in response to the surge in network demand, cloud computing responds by aggregating multiple physical network interface cards to increase network bandwidth, which can effectively avoid network interruptions. When demand drops, it will release some resources and reduce the load on the data center.

\subsection{Cloud computing basic architecture and service model}

The cloud computing architecture includes three basic levels, including infrastructure layer, platform layer and application layer. Each level is provided in the form of services. Therefore, in cloud computing, the entire cloud computing service can be divided into three categories according to the types of services it provides.

Iaa $\mathrm{S}$ refers to obtaining powerful computing, storage and network usage capabilities through various virtualization technologies, and using the network to provide consumers with a complete computer infrastructure to obtain services.

Paa $\mathrm{S}$ refers to the software $\mathrm{R} \& \mathrm{D}$ platform as a service, providing middleware platforms to users in the Paa S model, including databases and application servers.

$\mathrm{Saa} \mathrm{S}$ is a mode of providing software through the network. In order to meet the needs of its business applications, users apply to software service providers to use remote software functions without having to deploy and run related software locally.

\section{Overview of Financial Sharing Service Center}

Financial sharing service refers to the large amount of repetitive, easy-to-standardize and simplify accounting operations in the scattered business departments, which is concentrated in the independently operated business department, that is, the financial sharing service center, to perform process reengineering and standardization operations. It can improve business processing efficiency, reduce enterprise costs, strengthen enterprise management and control, improve customer satisfaction. The main features of the financial sharing service include the following aspects [8].

\subsection{Serviceability}

The financial sharing service center is a service provider and has completely changed the operation mode. Customers can choose services and participate in the supervision and evaluation of service quality. As a new type of customer service model, the financial sharing service aims to improve customer satisfaction, provide systematic and comprehensive services for enterprise customers, and charge corresponding fees.

\subsection{Unity}

The financial sharing service center has established a unified operation mode, operation process and execution standards to achieve cost reduction and efficiency increase.

\subsection{Scale}

Financial sharing services use computer information technology and Internet technology to integrate decentralized non-core financial services and provide value-added services to reduce unnecessary processing links, improve efficiency and reduce costs. The financial service sharing center uses computer information technology to form economies of scale.

\subsection{Technical}

The financial sharing service center needs very strong computer science and technology support, which to a large extent depends on highly integrated software systems, electronic communication systems and hardware support.

Compared with the traditional financial centralized processing, the financial shared service concentrates on decentralized business. The financial shared service condenses the advantages of decentralization and concentration. The comparative analysis results of the superiority of financial sharing services are shown in Figure 1. 


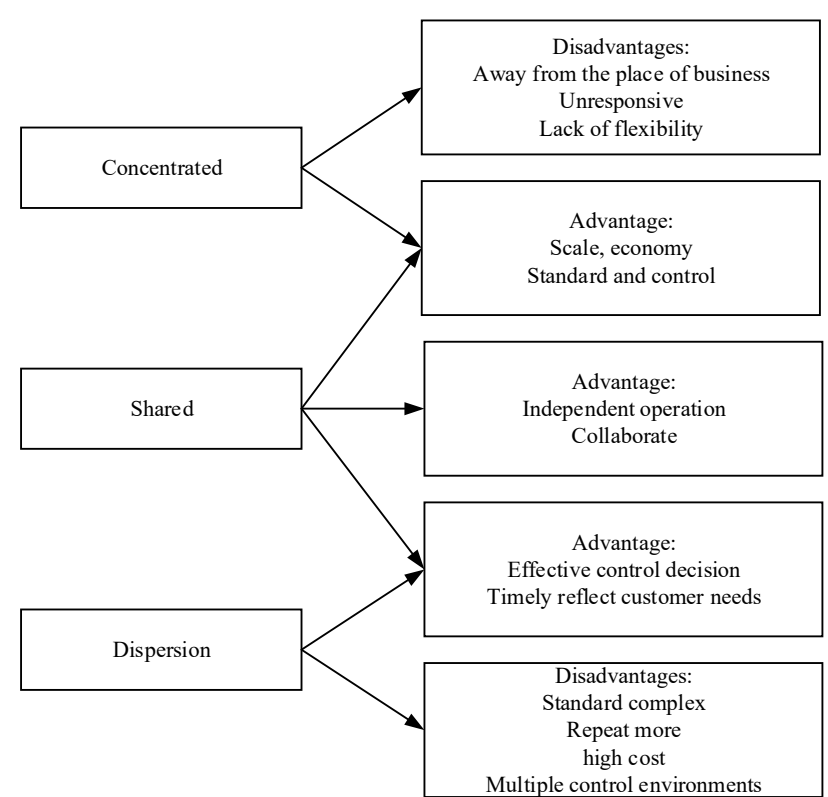

Fig1. Comparative analysis of the advantages of financial sharing services

\section{Construction of financial shared service center based on cloud computing}

The financial shared service center established based on cloud computing is technically divided into two cloud and client, and each part is composed of different levels [9]. The architecture of the financial shared service center based on cloud computing is shown in Figure 2.

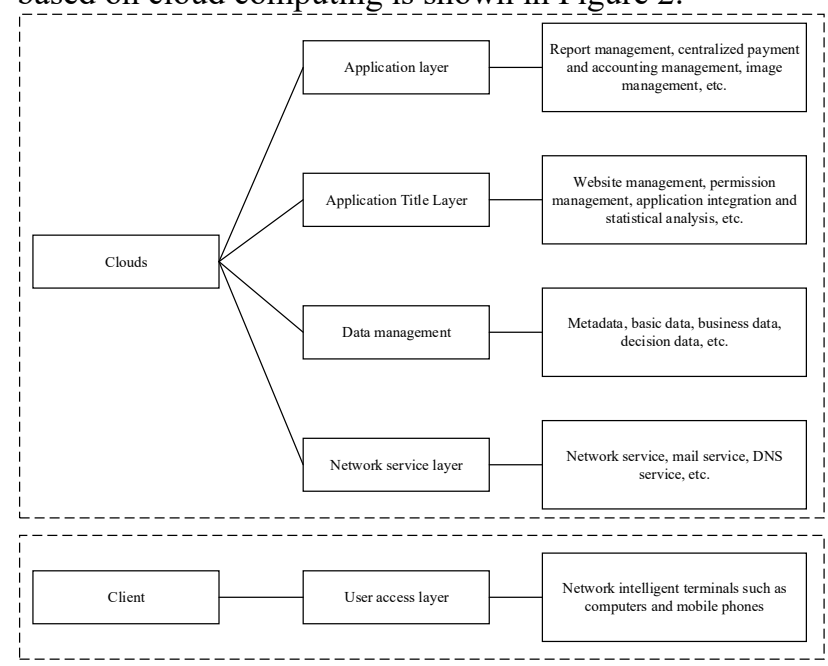

Fig2. Architecture of a financial shared service center based on cloud computing

\subsection{Organizational structure planning}

The financial sharing center serves other business units and is subordinate to the management of the group's financial director in terms of organizational relationships. It has a higher level, but has no leadership rights over the business units. This organizational structure is not conducive to the communication between employees of the financial sharing service center and business employees on official matters. The strategic position of the service center needs to be adjusted, the right boundaries of various structures within the enterprise group should be clearly demarcated, and the degree of cooperation between departments should be optimized. Give the shared service center certain management functions, specify the tasks of FSSC financial personnel, and clearly divide responsibilities.

\subsection{Reengineering the expense reimbursement process}

When employees need to reimburse expenses, they need to fill out reimbursement forms in a fixed format in the network reimbursement system. Employees put printed paper reimbursement slips and invoices in the invoice box, and the responsible person collects the bills and sends them to the financial sharing service center. The financial person who is responsible for expense reimbursement reviews the received bills; When in doubt, they will communicate with employees. If the review is passed, the payment process will begin. Due to the need to put paper bills in the bill box, ordinary finance employees collect and sort bills from branches and subsidiaries around the world, and then send them to the financial sharing service center.

\subsection{Payable process reengineering}

The accounts payable process is currently the most widely used business process in the company's financial shared service system. It has a high degree of standardization and automation functions and a large number of businesses. When the company generates purchasing demand, the purchasing department will place a unified purchase order, and the supplier will send the order to the regional financial sharing service center. If it is an invoice from an overseas company, the local financial officer will receive the invoice and paste the corresponding barcode, and scan it into the invoice database based on the supplier number. The first-level accounts payable employees are responsible for matching orders, receipts and invoices. If the match is successful, the system will automatically generate accounting entries and documents; failed matching invoices are recorded in the supplier database. Weekly accounts payable employees will run a payment plan in the system, print the payment list due this week, and submit to the corresponding management personnel to review the payment according to the company's payment authority. Based on the audit results, the cashier operates the online banking system, imports payment records, and submits them for review. After the reviewer approves in the online banking system according to his review authority, the payment will be paid to the corresponding supplier. The workflow of accounts payable is shown in Figure 3. 


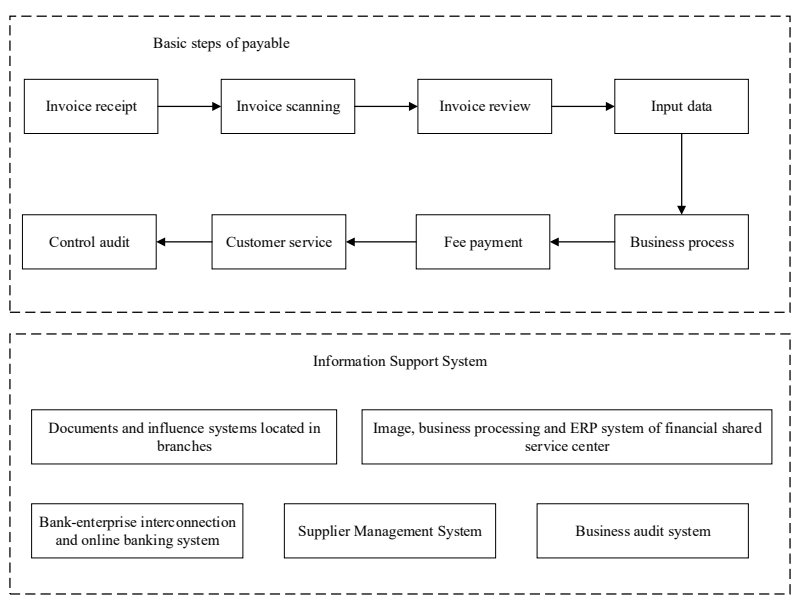

Fig3. The payable process of the cloud computing financial shared service center

\subsection{Reengineering of receivables process}

The accounts receivable business process mainly completes the settlement of invoices and accounts receivable reconciliation between the company and customers. The accounts receivable business process includes order acceptance, contract management, account processing and receipt confirmation, and customer verification. After obtaining the customer's order, it is necessary to record the key information of the contract in the system through manual input or image scanning and recognition. The shared service center performs revenue recognition for eligible contracts. After receiving the payment notice, the financial staff performs online banking verification in the online banking and fund management system, and after confirming the receipt, performs the accounting processing operations of the bank and accounts receivable in the system. Regularly check the contract and accounting information with the customer in the customer relationship management system, and update the customer's credit status in time to prevent credit risk. Reengineering of receivables process is shown in Figure 4.

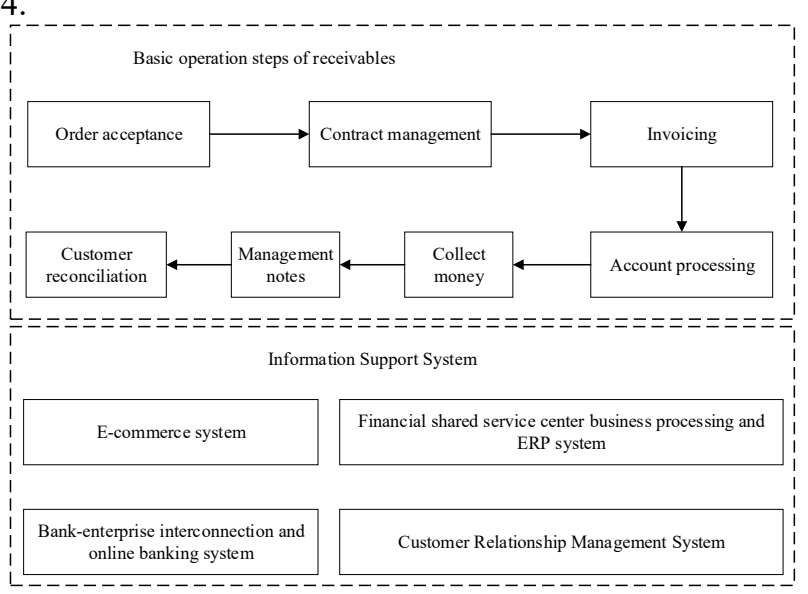

Fig4. Receivable process of cloud computing financial shared service center

\section{Conclusion}

Under the background of economic globalization, large group companies generally have cross-regional and transnational operations. With the development of the times, management ideas are constantly changing. Due to the increasingly fierce competition, the home appliance manufacturing industry is also facing various problems, such as excessive competition and sluggish consumer demand. Enterprises increasingly need financial support. The Financial Sharing Service Center can reflect the superiority of financial management. It is one of the important directions for most multinational group companies to carry out financial management reform. In China, the construction and operation are still in its infancy, and in various types of enterprise business, accounting and receivable management, expense reimbursement and other accounting calculations are currently the most widely used. Due to the development of informatization, the company has raised the financial requirements of management. The company must introduce new ideas and methods in financial management, and promote the transformation of the company's financial management model by building a financial shared service center. This article combines domestic and foreign research results to analyze the new trends of domestic financial sharing services, in-depth analysis of related theories, and research on a new financial management model based on cloud computing to build a financial sharing service center to provide a reference for corporate financial management.

\section{References}

1. L. M. Yang, Conception of Financial Management Model of Wuhan Iron and Steel Enterprise Group, Metallurgical Finance and Accounting, 1994, no.3, pp.12-13.

2. J. Xu, Discussion on the daily operation optimization of the financial shared service center-Taking Suning Tesco Group Co., Ltd. as an example. Finance and Accounting Newsletter, 2019, no.14, pp.75-79.

3. R. Y. Liu, S. Y. Xia, F. F. Mo, etc. Research on the Construction of Financial Shared Service Center Based on Grounded Theory_— Taking Z Company as an Example. Finance and Accounting, 2019, no.16, pp.34-37.

4. Q. He, New Trends in Corporate Financial Process Reengineering: Financial Shared Services, Accounting Newsletter, 2010, no.2, pp.71-73.

5. Y. Liu, Construction of enterprise ERP information system based on financial business process reengineering —_Tongda Refractory Group as an example, Accounting and Communications, 2017, no.2, pp.85-89.

6. P. Cheng, J. J. Wang, Research on the Optimization of Accounts Payable Process of RPA-based Financial Shared Service Center, Friends of Accounting, 2018, no. 19, pp.154-160.

7. P. Cheng, W. Y. Wang, Research on Optimization of Expense Reimbursement of Financial Shared Service 
Center Based on RPA, Friends of Accounting, 2018, no.13, pp.146-151.

8. X. Liu, New model of financial management: shared financial services, Continuing Education Research, 2011, no.3, pp.150-152.

9. L. C. Li, S. Wu, M. R. Fu, et al. Operation and optimization strategy of Petrochemical Group Financial Shared Service Center-Based on the pilot stage, Friends of Accounting, 2019, no.16, pp.118-122. 